Hum Genet (1990) 84:571-573

\title{
Screening for steroid sulfatase (STS) gene deletions by multiplex DNA amplification
}

\author{
Andrea Ballabio ${ }^{1,2, *}$, Joel E. Ranier ${ }^{2}$, Jeffrey S. Chamberlain ${ }^{2, * *}$, Massimo Zollo ${ }^{3}$, and C. Thomas Caskey ${ }^{1,2}$ \\ ${ }^{1}$ Howard Hughes Medical Institute and ${ }^{2}$ Institute for Molecular Genetics, Baylor College of Medicine, \\ One Baylor Plaza, Houston, TX 77030, USA \\ ${ }^{3}$ International Institute of Genetics and Biophysics, CNR, Via Marconi 10, Naples, Italy
}

Received August 8, 1989 / Revised November 8, 1989

Summary. Deletions are the most common molecular defect in steroid sulfatase (STS) deficiency. We describe the application of multiplex DNA amplification, by polymerase chain reaction, for deletion screening in patients with STS deficiency (STS-PCR). Genomic DNA from 38 unrelated patients was amplified using two sets of primers, corresponding to the $5^{\prime}$ and the $3^{\prime}$ ends of the STS gene. The analysis of the amplified products was always consistent with the results obtained by Southern analysis. This method represents a sensitive fast non-radioactive test for detecting STS gene deletions.

\section{Introduction}

$\mathrm{X}$-linked ichthyosis (XLI) as a result of steroid sulfatase (STS) deficiency is one of the most common X-linked disorders (see Shapiro 1989 for review). We have recently demonstrated, in a multicenter study, that 48 out of 57 unrelated patients with STS deficiency $(84 \%)$ display an entire gene deletion (Ballabio et al. 1989a).

Simultaneous amplification by polymerase chain reaction (PCR) of widely separated sequences (multiplex DNA amplification) is a fast non-radioactive method for scanning for deletions at a particular locus. We have previously shown the feasibility of this technique for deletion screening at the Duchenne muscular dystrophy (DMD) locus (Chamberlain et al. 1988). Here we describe the application of this method for deletion screening in STS deficiency.

\section{Materials and methods}

Patients' DNA was obtained from blood or fibroblasts and analyzed using the standard Southern blotting procedure. A full

\footnotetext{
* On leave from Department of Pediatrics, University of Reggio Calabria, Italy

** Current address: Department of Human Genetics, University of Michigan Medical School, Ann Arbor, Michigan, USA

Offprint requests to: A. Ballabio, Institute for Molecular Genetics, Baylor College of Medicine, One Baylor Plaza, Houston, TX
} 77030, USA length STS cDNA probe, 7A5B, obtained from the screening of a placental cDNA library using a previously isolated STS cDNA clone (Ballabio et al. 1987), was used in the Southern analysis.

The STS gene is composed of 10 exons that span a region of about $140 \mathrm{~kb}$ (Yen et al. 1989). Two sets of olinucleotide primers have been designed using sequence information obtained from previously isolated cDNA and genomic clones from the STS gene (Ballabio et al. 1987; Yen et al. 1989). The sequence of these primers and the size of the amplified regions are listed in Table 1 . They amplify two regions, one located approximately $900 \mathrm{bp}$ upstream from the initiation site of the STS gene (set 1), and the other containing the termination site in exon 10 (set 2). The primer sequences are sufficiently divergent from the corresponding Y-chromosome STS pseudogene regions to prevent spurious amplification of Y-specific sequences. A further set, corresponding to a 547 bp exon-containing region of the dystrophin gene (primer set $\mathrm{E}$ in Chamberlain et al. 1988), was used as an internal control for the reactions.

DNA amplification was performed essentially as previously described (Chamberlain et al. 1988). Primers were annealed at $60^{\circ} \mathrm{C}$ for $30 \mathrm{~s} ; 2 \mathrm{~min}$ extension times at $72^{\circ} \mathrm{C}$ were used. Thirty cycles of amplification were performed using the buffer described by Saiki et al. (1988).

\section{Results}

Figure 1A shows the results obtained by hybridization of probe $7 \mathrm{~A} 5 \mathrm{~B}$ with $E c o$ RI restricted DNA from 11 patients with STS deficiency and one male control. Both X and $\mathrm{Y}$ specific bands were detected in the control lane (lane 12), corresponding to the STS gene and pseudogene, respectively. $X$-specific bands were not detected in lanes $1,4,5,7,8,9$ and 10, indicating an entire STS gene deletion (the remaining bands correspond to the STS Y pseudogene). In lane 2, a partial deletion was observed, as previously reported (case AB, Ballabio et al. 1989a). A normal pattern was detected in lanes 3, 6 and 11 .

Figure 1B shows the STS amplification reaction products (STS-PCR) obtained with the DNA from the same patients as in Fig. 1A, and in the same order. Each sample displayed the presence of the DMD band (band a) demonstrating that the DNA was suitable for amplification. Amplification of the STS gene was entirely consistent with the Southern analysis shown in Fig. 1A. The 
Table 1. STS-PCR oligonucleotide primers

\begin{tabular}{llc}
\hline Primer set & Sequence & Amplified \\
\hline 1) 5'STS gene & F-5'GGCCTAGAAGAAGGTTGAAGGTCCC & $292 \mathrm{bp}$ \\
& R-5'AAGAGGTTGGATGAGATGGGCATAC & $363 \mathrm{bp}$ \\
2) 3'STS gene & F-5'GAAATCCTCAAAGTCATGCAGGAAG & \\
\hline
\end{tabular}

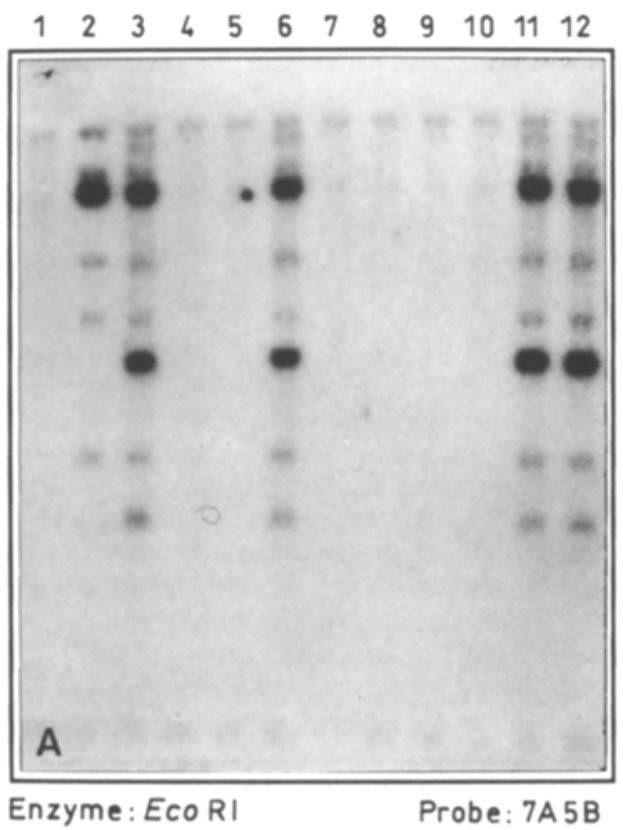

\section{$\begin{array}{lllllllllllll}1 & 2 & 3 & 4 & 5 & 6 & 7 & 8 & 9 & 10 & 11 & 12 & \mathrm{MW}\end{array}$}

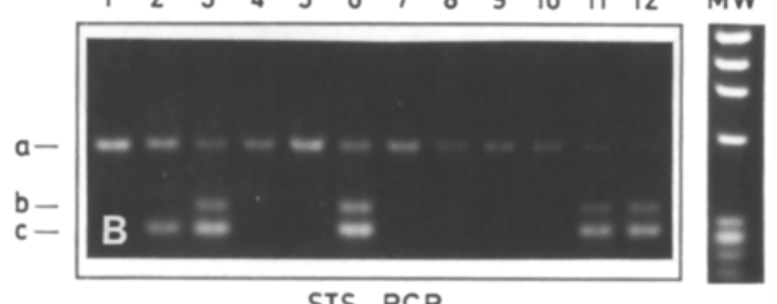

STS - PCR

Fig. 1. A Southern analysis of EcoRI digested DNA samples from 11 patients with STS deficiency (lanes 1-11) and one male control (lane 12) using the STS full length cDNA clone 7A5B. B Multiplex DNA amplification of the STS gene (STS-PCR) in 11 patients with STS deficiency (lanes 1-11, loaded in the same order as in $\mathbf{A}$ ) and one male control (lane 12), Band a corresponds to an exon of the DMD gene and was used as an internal control for the amplification. Bands $b$ and $c$ correspond to the $3^{\prime}$ and the $5^{\prime}$ ends of the STS gene, respectively. $M W X$ DNA digested with HaeIII

patients' DNA in lanes $1,4,5,7,8,9$ and 10 was unable to amplify either band b or c. DNA in lane 2 , from the patient with a deletion involving only the $3^{\prime}$ end of the gene, showed the absence of band $b$ and the presence of band $c$ (lane 2). DNA in lanes 3, 6, 11 and 12 showed a normal amplification pattern. A total of 38 Italian patients with STS deficiency have been analyzed by STSPCR and the results in each case are consistent with the Southern analysis, demonstrating an entire gene dele- tion in 32 cases, a partial deletion in one case, and a normal amplification pattern in 5 cases (data not shown).

\section{Discussion}

The application of DNA amplification to the molecular analysis of genetic disorders is becoming increasingly common (Erlich 1989). Multiplex DNA amplification is a facile rapid non-radioactive method for deletion screening at a particular locus, requiring less than $500 \mathrm{ng}$ DNA and allowing direct visualization on ethidium bromide stained gels of amplified products from the locus of interest. This technique is particularly useful for those diseases in which deletions are present in a large percentage of patients and in which molecular analysis by conventional Southern blotting would require hybridization with several probes. STS deficiency is a Mendelian disorder with an extremely high frequency of deletions (84\%) (Ballabio et al. 1989a). This makes it an ideal system for the use of a multiplex DNA amplification screening test.

We have designed two sets of primers amplifying regions at the $5^{\prime}$ and the $3^{\prime}$ ends of the STS gene. Although these primers would not recognize internal deletions, we were able to detect a deletion in $100 \%$ (33 cases) of the patients previously found to have deletions by conventional Southern analysis. Entire gene deletion is by far the most common observation in patients with STS deficiency, only one patient with an internal gene deletion being described (Yen et al. 1987). Therefore, our method represents a reliable screening test for STS gene deletions.

We have recently demonstrated that deletions of the STS gene may involve adjacent loci, sometimes causing contiguous gene syndromes (Ballabio et al. 1989b). Sequence analysis of these adjacent loci could enable expansion of the STS multiplex reaction to screen for contiguous gene syndromes. Such a reaction would provide a rapid method for the detection and partially characterization of deletions leading to contiguous gene syndromes throughout the Xp22.3 region. Multiplex PCR requires less than $5 \mathrm{~h}$ for complete analysis, and is therefore ideally suited for routine screening of patient DNA for deletions leading to genetic disease. Furthermore, the use of fluorescently labeled PCR primers enables almost fully automatic analysis of patient DNA with the consecutive use of an automatic thermocycler and a DNA sequencing apparatus (J.S.Chamberlain and C.T.Caskey unpublished observations). Multiplex amplification reactions could also be used to characterize rapidly somatic cell hybrids or to screen yeast artificial chromo- 
some (YAC) libraries for the identification of clones containing large regions of DNA flanking a particular locus. Such reactions should therefore prove useful both for routine disease screening and for gene mapping and cloning experiments related to the human genome project.

Acknowledgements. This work was in part supported by a grant from the Commission of the European Communities (grant SCE140), Texas Advanced Technology Program grant no. 3034, a Muscular Dystrophy Association Task Force on Genetics grant, and the Howard Hughes Medical Institute.

\section{References}

Ballabio A, Parenti G, Carrozzo R, Sebastio G, Andria G, Buckle V, Fraser N, Boyd Y, Craig I, Rocchi M, Romeo G, Jobsis AC, Persico MG (1987) Isolation and characterization of a steroid sulfatase cDNA clone: genomic deletions in patients with X-chromosome-linked ichthyosis. Proc Natl Acad Sci USA $84: 4519-4523$

Ballabio A, Carrozzo R, Parenti GF, Gil A, Zollo M, Persico MG, Gillard E, Affara N, Yates J, Ferguson-Smith MA, Frants RR, Eriksson AW, Andria G (1989a) Molecular heterogeneity of steroid sulfatase deficiency: a multicenter study on 57 unrelated patients, at DNA and protein levels. Genomics 4:36-40
Ballabio A, Bardoni B, Carrozzo R, Andria G, Bick D, Campbell L, Hamel B, Ferguson-Smith MA, Gimelli G, Fraccaro M, Maraschio P, Zuffardi O, Guioli S, Camerino G (1989b) Contiguous gene syndromes due to deletions in the distal short arm of the human X chromosome. Proc Natl Acad Sci 86:1000110005

Chamberlain JS, Gibbs RA, Ranier JE, Nguyen PN, Caskey CT (1988) Deletion screening of the Duchenne muscular dystrophy locus via multiplex DNA amplification. Nucleic Acids Res 16:11141-11156

Erlich HA (ed) (1989) PCR technology; principles and applications of DNA amplification. Stockton Press, New York

Saiki RK, Gelfand DH, Stoffel S, Scharf SJ, Higuchi R, Horn GT, Mullis KB, Erlich HA (1988) Primer-directed enzymatic amplification of DNA with a thermostable DNA polymerase. Science 236:487-491

Shapiro LJ (1989) Steroid sulfatase deficiency and X-linked ichthyosis. In: Scriver CR, Beaudet AL, Sly WS, Valle D (eds) The metabolic basis of inherited disease, 6th edn. McGrawHill, New York, pp 1945-1964

Yen PH, Allen E, Marsh B, Mohandas T, Wang N, Taggart RT, Shapiro LJ (1987) Cloning and expression of steroid sulfatase cDNA and the frequent occurrence of deletions in STS deficiency: implications for $\mathrm{X} / \mathrm{Y}$ interchange. Cell 49:443-454

Yen PH, Marsh B, Allen E, Tsai SP, Ellison J, Connolly L, Neiswanger K, Shapiro LJ (1989) The human X-linked steroid sulfatase gene and a $\mathrm{Y}$-encoded pseudogene: evidence for an inversion of the $\mathrm{Y}$ chromosome during primate evolution. Cell $55: 1123-1135$
Note added in proof. Since this paper was submitted, the PCR primers described here have been successfully used for the isolation of five yeast artificial chromosome (YAC) clones spanning the entire STS gene and flanking loci. 